\title{
Prevalence and associated factors of Chlamydia trachomatis and Neisseria gonorrhoeae among female commercial sex workers in Hawassa City, Southern Ethiopia
}

\author{
Alelign Tadele ${ }^{1}$, Siraj Hussen ${ }^{2 *}$ and Techalew Shimelis ${ }^{2}$
}

\begin{abstract}
Background: Chlamydia trachomatis and Neisseria gonorrhoeae are the most common pathogens causing genital tract infections. Female commercial sex workers (FCSWs) are the key population to be affected by sexually transmitted infections (STIS). In Ethiopia, little is known about C. trachomatis and N. gonorrhoeae infections in most at risk population. Therefore, this study aimed to assess the prevalence of these bacterial STIs among FCSWs.

Methods: A cross-sectional study was conducted at the confidential clinic in Hawassa City, Southern Ethiopia from January to April, 2017. A total of 338 FCSWs were selected using systematic random sampling technique and enrolled in the study. Information about socio-demography and associated factors was collected using structured questionnaires. Endocervical swab samples were also collected from the study participants and tested for C. trachomatis using rapid immunochromatography assay. Samples were also cultured to isolate $N$. gonorrhoeae according to the standard bacteriological method.

Results: The prevalence of $\mathrm{N}$. gonorrhoeae and C. trachomatis among FCSWs was 3.3\% [95\% confidence interval (CI): $1.5-5.3]$ and $6.8 \%$ (95\% Cl: 3.9-9.5), respectively. FCSWs who consistently practiced sex without condom in the last 6 months had 6.3 times (AOR 6.3; 95\% Cl 1.61-24.86, $P=0.008$ ), and 4.0 times (AOR 4.0; 95\% Cl 1.06-15.31, $p=0.040$ ) higher odds of acquiring $N$. gonorrhoeae and C. trachomatis infections, respectively.

Conclusion: The observed rates of $C$. trachomatis and N. gonorrhoeae infections among FCSWs warrant the need to strengthen intervention efforts. In this regard, screening FCSWs for the specified infections and improving the practice of condom use would be important.
\end{abstract}

Keywords: Chlamydia trachomatis, Neisseria gonorrhoeae, Female commercial sex workers, Hawassa, Ethiopia

\section{Background}

Neisseria gonorrhoea and Chlamydia trachomatis are among the main pathogens causing sexually transmitted infections (STIs) [1, 2]. The World Health Organization (WHO) estimated that 50 million women worldwide were newly infected with $C$. trachomatis; of which, 34 million were in Sub-Saharan Africa and South/Southeast Asia [3]. With annual 82 million estimated cases globally, $N$. gonorrhoeae has been recognized as one of the

\footnotetext{
* Correspondence: sirajhu123@gmail.com

${ }^{2}$ School of Medical Laboratory Science, College of Medicine and Health

Sciences, Hawassa University, Hawassa, Ethiopia

Full list of author information is available at the end of the article
}

major bacterial STIs. An estimated 17 and 27 million new cases annually occurred in Africa and in Southern Asia, respectively [1].

In women, urogenital C. trachomatis and $N$. gonorrhoeae infections cause broad spectrum of clinical manifestations, including urethritis, cervicitis, and pelvic inflammatory disease. If untreated, these infections may lead to serious complications, including ectopic pregnancy and tubal infertility [4]. However, over $50 \%$ of women with gonorrhea and $75 \%$ of women with C. trachomatis remain asymptomatic during the entire infection process. Thus, they are unaware of their infection

(c) The Author(s). 2019 Open Access This article is distributed under the terms of the Creative Commons Attribution 4.0 International License (http://creativecommons.org/licenses/by/4.0/), which permits unrestricted use, distribution, and reproduction in any medium, provided you give appropriate credit to the original author(s) and the source, provide a link to the Creative Commons license, and indicate if changes were made. The Creative Commons Public Domain Dedication waiver (http://creativecommons.org/publicdomain/zero/1.0/) applies to the data made available in this article, unless otherwise stated. 
to seek treatment, which facilitates further spread to their sexual partners $[5,6]$.

It was reported that chlamydial infection often occurred among women aged 15-29 years due tohost related factors such as the number of sexual partner, contraceptive use, sexual preference, and population mobility [5]. Female commercial sex workers (FCSWs) are at higher risk of contracting the infection [7], due to their social vulnerability and work related factors, like a history of having multiple sexual partners, inconsistent condom use, and a history of having STIs $[8,9]$. FCSWs also link the spread of STIs to the general population through their clients [10].

In Ethiopia, the epidemiology of $C$. trachomatis and $N$. gonorrhoeae infection is not well described due to the asymptomatic nature of the infection and lack of laboratory diagnostic facilities. However, a hospital-based study that investigated women of reproductive age (15-49 years) reported prevalence of $C$. trachomatis and $N$. gonorrhoeae was 18.9 and $0.31 \%$, respectively [11]. It would be important to study FCSWs to emphasize the need of strengthening intervention strategies that address the risk group. Therefore, this study aimed to assess the prevalence and associated risk factors of $C$. trachomatis and N. gonorrhoeae infections among FCSWs. The findings from this study help public health experts and other concerned bodies to design and undertake evidence-based interventions.

\section{Methods}

\section{Study area and period}

An institution-based cross-sectional study was conducted in Hawassa City, Southern Ethiopia from January to April, 2017. The city is situated on the shore of Lake Hawassa, in the Great Rift Valley, and located $275 \mathrm{~km}$ far south of Addis Ababa. Hawassa had a total population size of 343,175 people in the year 2014. FCSW is defined as any female, who practices sexual activity with a man in return for money, irrespective of the site of operation (i.e: street, bars, home and hotel). The only confidential clinic in the city is managed by the Family Guidance Association Ethiopia. The clinic has been serving FCSWs since August 2012, and provides comprehensive services including medical care, family planning, HIV voluntary counseling and testing (VCT), safe abortion, prevention of mother-to-child transmission (PMTCT), antenatal care (ANC), and management of STIs.

\section{Population}

FCSWs, who received service in the confidential clinic during the study period, were the source population. FCSWs, who visited the confidential clinic during the study period, were eligible. FCSWs who attended the clinic more than once, those on STI treatment, and who were sick and unable to take part in the interview, were excluded.

\section{Sample size and sampling technique}

The sample size was determined using a single population proportion formula to estimate the prevalence of $C$. trachomatis and N. gonorrhoeae infections among FCSWs. The sample size was calculated based on the following assumptions: prevalence of $N$. gonorrhoeae among FCSWs in Democratic Republic of Congo (7.8\%) [12], 95\% confidence interval, and 3\% precision Further, considering a $10 \%$ non-response rate, the sample size was calculated to be 338. A systematic random sampling technique was used to recruit FCSWs attending the Confidential Clinic. Considering a four-month study period, a total of 592 FCSWs were expected to visit the clinic according to the clinic plan and the past 4 month's performance document review. This estimate was divided by the sample size to determine the sample interval ( $\mathrm{k}$ value), which would be 1.8. Thus, the 1st served client and every 2 nd client afterwards was invited to participate in the study until the required sample size would be achieved.

\section{Data collection method \\ Data collection instrument and processing}

Interview A pre-tested and structured questionnaire was used to collect information on socio-demographic characteristics (age, residence, marital status, and educational level) and sexual related factors (consistent condom use in the last 6 months, age at first sex, years in sex work, self-reported history of STIs, number of client per week in the last 6 months, having regular partner) of study participants. Data was collected through face-to-face interview by two midwife nurses.

\section{Laboratory methods \\ Sample collection and transportation}

The midwife nurses collected two endocervical swab samples from each study participant. One swab was collected for immediate testing of $C$. trachomatis, and the second swab was placed in Amies transport media and transported to Hawassa University Comprehensive Specialized Hospital using cold box for culturing of $N$. gonorrhoeae.

\section{Isolation of Neisseria gonorrhoeae}

Swab samples for N. gonorrhoeae were inoculated on modified Thayer-Martin agar and placed in a candle jar with $5-10 \% \mathrm{CO}_{2}$. The inoculated plates were incubated at $37^{\circ} \mathrm{c}$ for $24-72 \mathrm{~h}$. Bacterial growth was identified based on characteristic colony morphology, Gram reaction, and biochemical testing. 


\section{Testing of chlamydia antigen}

Chlamydia antigen was detected by laboratory technologist in the confidential clinic using the onsite chlamydial rapid test kit (CTK Biotech, Inc., USA). This is a lateral flow chromatography immune assay based on double antibody-switched technique, which utilizes a unique part of the mouse monoclonal antibody to selectively identify $C$. trachomatis antigen in the specimen. Tests were performed according to the manufacturer instruction. A swab was inserted in to the sample extraction tube. Then four drops $(200 \mu \mathrm{l})$ of buffer A were added and incubated at room temperature for $5 \mathrm{~min}$. Further, four drops $(200 \mu \mathrm{l})$ of buffer B were added and mixed by rotating the swab for $10 \mathrm{~s}$ and incubated for $1 \mathrm{~min}$. Two drops of extract solution were dispensed to the sample pad and the result was read after $15 \mathrm{~min}$. A negative result was indicated if only the ' $\mathrm{C}$ ' band developed. Also a positive result was indicated if both ' $\mathrm{C}$ ' and ' $\mathrm{T}$ ' bands developed. If ' $\mathrm{C}$ ' band did not develop, the result was reported as invalid and repeated with new device. The sensitivity and specificity of the test kit was 94.1 and $97.4 \%$, respectively.

\section{Quality control}

The questionnaire was prepared in English language and translated to Amharic language and then back translated to English version. One week prior to data collection, the questionnaire was pre-tested on $5 \%$ of the required sample size at USAID Mulu HIV Prevention Project Southern Area Office, Ethiopia clinic (a site different from the actual study site) to ensure questions were unambiguous. Prior to the beginning of any data collection, all data collectors were trained by the principal investigator. The collected data was checked daily for consistency and accuracy. The quality of test results was maintained using the internal quality control of the test kits.

\section{Data analysis}

Data entry and analysis was done using SPSS version 23 computer software. Data was summarized using descriptive statistics and presented using tables and figures. Bivariate logistic regression analysis was used to assess the association between rate of infection and sociodemographic characteristics and related factors. Multivariable logistic regression analysis was performed taking together those socio-demographic and related factors with a $p$-value less than 0.25 in bivariate logistic regression analysis. Odds ratio (OR) and its corresponding 95\% confidence interval (CI) was calculated to measure the strength of association. In all cases, p- value less than 0.05 was considered to be statistically significant.

\section{Operational definitions}

$>$ Consistent condom use: the practice of using condom in every sexual intercourse.

$>$ Female commercial sex worker: Any female, who undertakes sexual activity with a man in return for money, irrespective of the site of operation (i.e., street, bars, home, hotel).

\section{Results}

\section{Socio-demography}

A total of 338 women, who attended the confidential clinic, were enrolled in this study. The mean age of the participants was 22.1 years (standard deviation (SD), 5.52; range, $15-39$ years), and the majority (63.9\%) were in the age category of 15-24 years. Rural residents and those with no formal education accounted for 59.2 and $30.8 \%$, respectively (Tables 1 and 2).

\section{Prevalence of Neisseria gonorrhoeae and Chlamydia trachomatis}

The prevalence of $N$. gonorrhoeae and C. trachomatis was 3.3 and $6.8 \%$, respectively. Co-infection of N. gonorrhoeae and C. trachomatis was detected in $0.6 \%$ of the FCSWs. A higher rate of $N$. gonorrhoeae (4.2\%) and C. trachomatis (7.9\%) was observed among FCSWs in the age range 15-24 years. N. gonorrhoeae and C. trachomatis infections were detected in 3.6 and $8 \%$ of urban residents, and in 7.7 and $9.6 \%$ of those FCSWs with no formal education, respectively (Tables 1 and 2).

In bivariate analysis, the prevalence of $N$. gonorrhoeae infection was shown to be higher among FCSWs with no formal education compared to those who had secondary and above educational level (COR 9.2; 95\% CI 1.13-74.62). However, there was no statistically significant association between $N$. gonorrhoeae infection and site of residence, marital status, and age of the participants. In further analysis, after adjustment for those significantly associated variables using multivariable logistic regression analysis, the association between $N$. gonorrhoeae infection and educational status was not found to be statistically significant (AOR 5.3; 95\% CI 0.60-46.57).

\section{Self-reported factors for $\mathbf{N}$. gonorrhoeae and C. trachomatis infection}

The exposure to different factors of $N$. gonorrhoeae and $C$. trachomatis infections among the study participants is presented in Tables 3 and 4. The majority (90.2\%) of the participants responded they regularly used condom during sexual practice with their clients. Seventy nine percent of the respondents had $\geq 7$ clients per week within the last 6 months. Most (84.9\%) of the study participants were engaged in sex work for $\leq 5$ years, and $67.8 \%$ of the respondents had first 
Table 1 Distribution of N. gonorrhoeae by socio-demographic characteristics of FCSWs at a confidential clinic in Hawassa city, Southern Ethiopia, 2017

\begin{tabular}{|c|c|c|c|c|c|c|}
\hline \multirow{2}{*}{$\begin{array}{l}\text { Socio- } \\
\text { demographic } \\
\text { variables }\end{array}$} & \multirow[t]{2}{*}{ Categories } & \multicolumn{5}{|c|}{ Neisseria gonorrhea } \\
\hline & & No. tested (\%) & No. positive (\%) & COR (95\% Cl) & $\mathrm{AOR}(95 \% \mathrm{Cl})$ & P-Value \\
\hline \multirow[t]{3}{*}{ Age(in years) } & $15-24$ & $216(63.9)$ & $9(4.2)$ & $2.28(0.49-10.96)$ & - & - \\
\hline & $25-34$ & $109(32.2)$ & $2(1.8)$ & 1 & & \\
\hline & 35 and above & $13(3.8)$ & $0(0.0)$ & & & \\
\hline \multirow[t]{2}{*}{ Residence before } & Urban & $138(40.8)$ & $5(3.6)$ & $1.22(0.36-4.07)$ & - & - \\
\hline & Rural & $200(59.2)$ & $6(3.0)$ & 1 & & \\
\hline \multirow[t]{3}{*}{ Marital Status } & Single & $186(55.0)$ & $6(3.2)$ & $1.70(0.20-14.45)$ & - & - \\
\hline & Married & $52(15.4)$ & $1(1.9)$ & 1 & & \\
\hline & Widowed \& Divorced & $100(29.6)$ & $4(4.0)$ & $2.12(0.23-19.52)$ & - & - \\
\hline \multirow[t]{3}{*}{ Educational Status } & No formal education & $104(30.8)$ & $8(7.7)$ & $9.16(1.13-74.62)^{*}$ & $5.28(0.60-46.57)$ & 0.134 \\
\hline & Primary education & $123(36.4)$ & $2(1.6)$ & $1.82(0.16-20.33)$ & $1.33(0.11-15.42)$ & 0.826 \\
\hline & Secondary and above & $111(32.8)$ & $1(0.9)$ & 1 & 1 & \\
\hline
\end{tabular}

NB: * Candidate variable for multivariable analysis at $P<0.25 *$ variable significant at $P<0.05$

$C O R$ crude odds ratio, $A O R$ adjusted odds ratio, $C l$ confidence interval, $P-V p$-value, 1 reference

sex after the age of 15 years. About $39.1 \%$ of the study participants had a history of STIs, and 68.3\% used contraceptives.

FCSWs, who did not use condom regularly, had a higher rate of $N$. gonorrhoeae infection (15.2\%) compared to those who consistently used condom (2.2\%) (COR 8.9; 95\% CI 2.56-31.00). Similarly, the association between $C$. trachomatis infection and practice of condom use was found to be statistically significant (COR 4.86; 95\% CI 1.86-12.89). Further, FCSWs, who did not use condom with regular partners, were at higher odds of having C. trachomatis infection compared to those who consistently use condom (COR 4.4; 95\% CI 1.0617.95).
In multivariable logistic regression analysis, FCSWs, who did not use condom regularly in the last 6 months, were at higher risk of acquiring N. gonorrhoeae (AOR 6.3; 95\% CI 1.61-24.86,) and C. trachomatis (COR 4.28; 95\% CI 1.06-15.31) infections compared to those who regularly used condom. However, there was no statistically significant association between $N$. gonorrhoeae /C. trachomatis infection and other variables such as place of work, using contraceptives, drinking alcohol before sex, and age at starting sex work.

\section{Discussion}

C. trachomatis and N. gonorrhoeae infections are an important public health problem worldwide. Most

Table 2 Distribution of C. trachomatis by socio-demographic characteristics of FCSWs at a confidential clinic in Hawassa City, Southern Ethiopia, 2017

\begin{tabular}{|c|c|c|c|c|c|c|}
\hline \multirow{2}{*}{$\begin{array}{l}\text { Socio- } \\
\text { demographic } \\
\text { variables }\end{array}$} & \multirow[t]{2}{*}{ Categories } & \multicolumn{5}{|c|}{ Chlamydia trachomatis } \\
\hline & & No. tested (\%) & No. positive (\%) & COR $(95 \% \mathrm{Cl})$ & $\mathrm{AOR}(95 \% \mathrm{Cl})$ & $P$-Value \\
\hline \multirow[t]{3}{*}{ Age(in years) } & $15-24$ & $216(63.9)$ & $17(7.9)$ & $1.46(0.56-3.83)$ & - & - \\
\hline & $25-34$ & $109(32.2)$ & $6(5.5)$ & 1 & & \\
\hline & 35 and above & $13(3.8)$ & $0(0.0)$ & & & \\
\hline \multirow[t]{2}{*}{ Residence before } & Urban & $138(40.8)$ & $11(8.0)$ & $1.35(0.59-3.17)$ & - & - \\
\hline & Rural & $200(59.2)$ & $12(6.0)$ & 1 & & \\
\hline \multirow[t]{3}{*}{ Marital Status } & Single & $186(55.0)$ & $11(5.9)$ & $1.01(0.28-3.83)$ & - & - \\
\hline & Married & $52(15.4)$ & $3(5.8)$ & 1 & & \\
\hline & Widowed \& Divorced & $100(29.6)$ & $9(9.0)$ & $1.58(0.42-6.25)$ & - & - \\
\hline \multirow[t]{3}{*}{ Educational Status } & No formal education & $104(30.8)$ & $10(9.6)$ & $1.86(0.65-5.32)^{*}$ & $1.42(0.31-6.59)$ & 0.652 \\
\hline & Primary education & $123(36.4)$ & $7(5.7)$ & $1.06(0.34-3.24)$ & $0.93(0.19-4.43)$ & 0.927 \\
\hline & Secondary and above & $111(32.8)$ & $6(5.4)$ & 1 & 1 & \\
\hline
\end{tabular}

$N B:{ }^{*}$ Candidate variable for multivariable analysis at $P<0.25{ }^{*}$ variable significant at $P<0.05$

$C O R$ crude odds ratio, $A O R$ adjusted odds ratio, $C l$ confidence interval, $P-V p$-value, 1 reference 
Table 3 Bivariate and multivariable analysis of factors associated with N. gonorrhoeae infection among FCSWs in Hawassa City, Southern Ethiopia, 2017

\begin{tabular}{|c|c|c|c|c|c|c|}
\hline \multirow[t]{2}{*}{ Socio-demographic variables } & \multirow[t]{2}{*}{ Categories } & \multicolumn{5}{|c|}{ Neisseria gonorrhea } \\
\hline & & No. tested (\%) & No. positive (\%) & COR $(95 \% \mathrm{Cl})$ & $\mathrm{AOR}(95 \% \mathrm{Cl})$ & $P$-Value \\
\hline \multirow[t]{2}{*}{ Years in sex work } & $<5$ yrs & $287(84.9)$ & $8(2.8)$ & 1 & & \\
\hline & $>5 \mathrm{yrs}$ & $51(15.1)$ & $3(5.9)$ & $2.28(0.56-8.51)$ & - & - \\
\hline \multirow[t]{3}{*}{ Place of work } & Home & $16(4.8)$ & $1(6.3)$ & $2.65(0.28-25.25)$ & - & - \\
\hline & Street & $159(47.0)$ & $6(3.8)$ & $1.55(0.43-5.63)$ & - & - \\
\hline & Hotel / bar & $163(48.2)$ & $4(2.5)$ & 1 & & \\
\hline \multirow[t]{2}{*}{ Age at first sex } & $<15 \mathrm{yrs}$ & $109(32.2)$ & $4(3.7)$ & $1.21(0.35-4.23)$ & - & - \\
\hline & $>15 y r s$ & $229(67.8)$ & $7(3.1)$ & 1 & & \\
\hline \multirow[t]{3}{*}{ Age at starting sex work } & $<15 \mathrm{yrs}$ & $16(4.7)$ & $1(6.3)$ & $0.49(0.14-1.74)$ & - & - \\
\hline & $15-19 y r s$ & $214(63.3)$ & $5(2.3)$ & 1 & & \\
\hline & $>20 y r s$ & $108(32.0)$ & $5(4.6)$ & $1.37(0.15-12.57)$ & - & - \\
\hline \multirow[t]{2}{*}{ No of customers/ week } & $<7$ clients & $267(79.0)$ & $9(3.4)$ & $1.20(0.25-5.70)$ & - & - \\
\hline & $>7$ clients & $71(21.0)$ & $2(2.8)$ & 1 & & \\
\hline \multirow[t]{2}{*}{ Consistent condom use } & Yes & $305(90.2)$ & $6(2.0)$ & 1 & 1 & \\
\hline & No & $33(9.8)$ & $5(15.2)$ & $8.89(2.56-31.00)^{*}$ & $6.31(1.61-24.86)$ & $0.008^{*}$ \\
\hline \multirow[t]{2}{*}{ Having regular sexual partner } & Yes & $201(59.5)$ & $6(3.0)$ & 1 & & \\
\hline & No & $137(40.5)$ & $5(3.6)$ & $1.23(0.37-4.12)$ & - & - \\
\hline \multirow[t]{2}{*}{ Consistent condom use with regular partner } & Yes & $187(93.0)$ & $4(2.1)$ & 1 & 1 & \\
\hline & No & $14(7.0)$ & $1(7.1)$ & $3.52(0.37-33.81)^{*}$ & $2.56(0.39-17.46)$ & 0.319 \\
\hline \multirow[t]{2}{*}{ Not using condom for better payment } & Yes & 19(5.6) & $2(10.5)$ & $4.05(0.81-20.23)$ & - & - \\
\hline & No & 319(94.4) & $9(2.8)$ & 1 & & \\
\hline \multirow[t]{2}{*}{ Using contraceptives } & Yes & $231(68.3)$ & $6(2.6)$ & 1 & & \\
\hline & No & 107(31.7) & $5(4.7)$ & $1.84(0.55-6.16)$ & - & \\
\hline \multirow[t]{2}{*}{ Drinking alcohol before sex } & Yes & $276(81.7)$ & $9(3.3)$ & $1.01(0.21-4.80)$ & - & - \\
\hline & No & $62(18.3)$ & $2(3.2)$ & 1 & & \\
\hline \multirow[t]{2}{*}{ Self-reported history of STIs } & Yes & $132(39.1)$ & $7(5.3)$ & $2.83(0.81-9.86)^{*}$ & $2.83(0.76-10.52)$ & 0.122 \\
\hline & No & $206(60.9)$ & $4(1.9)$ & 1 & 1 & \\
\hline
\end{tabular}

NB: *Candidate variable for multivariate analysis at $P<0.25{ }^{*}$ variable significant at $P<0.05$

COR crude odds ratio, $A O R$ adjusted odds ratio, $C l$ confidence interval, $P$-V $p$-value, 1 reference, ST/s sexual transmitted infections, yrs. years, No total number

developed countries have implemented specific chlamydial and gonococal infection control programs that include case management, opportunistic screening of high risk groups, and annual screening of sexually active women aged $<25$ years. However, in developing countries like Ethiopia where laboratory facilities are limited, the management of STIs is still based on non-specific syndromic approach, which results in over-prescription of drugs. Further, the epidemiology of STIs is not well described in Ethiopian settings so as to design and implement evidence-informed intervention strategies. This study aimed to assess the prevalence and associated risk factors of C. trachomatis and $N$. gonorrhoeae infections among FCSWs.

In this study, the prevalence of $N$. gonorrhoeae and $C$. trachomatis among FCSWs was 3.3 and 6.8\%, respectively. The observed rate of $C$. trachomatis infection was in agreement with results reported in Congo (8.4\%) [13], Kenya (8\%) [14], Netherlands (7.1\%) [15], and Barcelona (4.7\%) [16]. However, a contrasting lower result was reported in Kenya (3.1\%) [13], and higher results were reported in Senegal (20\%) [17] and Côte d'Ivoire (11.8\%) [18]. These difference in prevalence may be due to a varying distribution of risk factors in different countries and dissimilar laboratory methods employed.

Moreover, the observed rate of $N$. gonorrhoeae in the current study was consistent with findings reported in Mexico (3.7\%) [19], Netherlands (2.6\%) [15], and Peru (1.6\%) [20]. However, as the studies used highly sensitive laboratory techniques such as polymerase chain reaction (PCR) and nucleic acid amplified tests (NAAT) [15, 19, 20], the epidemiological significance of gonorrhea might be higher in our setting. In contrast to our finding, higher rates of gonorrhea were reported in Ghana 
Table 4 Bivariate and multivariable analysis of factors associated with C. trachomatis infection among FCSWs in Hawassa City, Southern Ethiopia, 2017

\begin{tabular}{|c|c|c|c|c|c|c|}
\hline \multirow[t]{2}{*}{ Socio-demographic variables } & \multirow[t]{2}{*}{ Categories } & \multicolumn{5}{|c|}{ Chlamydia trachomatis } \\
\hline & & No. tested (\%) & No. positive (\%) & COR $(95 \% \mathrm{Cl})$ & $\mathrm{AOR}(95 \% \mathrm{Cl})$ & $P$-Value \\
\hline \multirow[t]{2}{*}{ Years in sex work } & $<5$ yrs & $287(84.9)$ & $19(6.6)$ & 1 & & \\
\hline & $>5 \mathrm{yrs}$ & $51(15.1)$ & $4(7.8)$ & $1.20(0.39-3.69)$ & - & - \\
\hline \multirow[t]{3}{*}{ Place of work } & Home & $16(4.8)$ & $2(12.5)$ & $2.18(0.44-10.98)$ & - & - \\
\hline & Street & $159(47.0)$ & $11(6.9)$ & $1.14(0.47-2.76))$ & - & - \\
\hline & Hotel / bar & $163(48.2)$ & $10(6.1)$ & 1 & & \\
\hline \multirow[t]{2}{*}{ Age at first sex } & $<15 \mathrm{yrs}$ & $109(32.2)$ & $6(5.5)$ & 1 & & \\
\hline & $>15 \mathrm{yrs}$ & $229(67.8)$ & $17(7.4)$ & $1.37(0.53-3.60)$ & - & - \\
\hline \multirow[t]{3}{*}{ Age at starting sex work } & $<15 \mathrm{yrs}$ & $16(4.7)$ & $1(6.3)$ & $0.73(0.29-1.72)$ & - & - \\
\hline & $15-19 y r s$ & $214(63.3)$ & $13(6.1)$ & 1 & & \\
\hline & $>20 \mathrm{yrs}$ & $108(32.0)$ & $9(8.3)$ & $0.71(0.09-6.21)$ & - & - \\
\hline \multirow[t]{2}{*}{ No of customers/ week } & $<7$ clients & $267(79.0)$ & $17(6.4)$ & 1 & & \\
\hline & $>7$ clients & $71(21.0)$ & $6(8.5)$ & $1.35(0.52-3.58)$ & - & - \\
\hline \multirow[t]{2}{*}{ Consistent condom use } & Yes & $305(90.2)$ & $16(5.2)$ & 1 & 1 & \\
\hline & No & $33(9.8)$ & $7(21.2)$ & $4.86(1.86-12.89)^{*}$ & $4.03(1.06-15.31)$ & $0.040^{*}$ \\
\hline \multirow[t]{2}{*}{ Having regular sexual partner } & Yes & $201(59.5)$ & $14(7.0)$ & $1.07(0.45-2.53)$ & - & - \\
\hline & No & $137(40.5)$ & $9(6.6)$ & 1 & & \\
\hline \multirow[t]{2}{*}{ Consistent condom use with regular partner } & Yes & $187(93.0)$ & $11(5.9)$ & 1 & 1 & \\
\hline & No & $14(7.0)$ & $3(21.4)$ & $4.36(1.06-17.95)^{*}$ & $4.01(0.88-18.35)$ & 0.073 \\
\hline \multirow[t]{2}{*}{ Not using condom for better payment } & Yes & 19(5.6) & $2(10.5)$ & $1.67(0.36-7.71)$ & - & - \\
\hline & No & 319(94.4) & $21(6.6)$ & 1 & & \\
\hline \multirow[t]{2}{*}{ Using contraceptives } & Yes & $231(68.3)$ & $15(6.5)$ & 1 & & \\
\hline & No & 107(31.7) & $8(7.5)$ & $1.16(0.48-2.84)$ & - & - \\
\hline \multirow[t]{2}{*}{ Drinking alcohol before sex } & Yes & $276(81.7)$ & $20(7.2)$ & $1.54(0.44-5.34)$ & - & - \\
\hline & No & $62(18.3)$ & $3(4.8)$ & 1 & & \\
\hline \multirow[t]{2}{*}{ Self-reported history of STIs } & Yes & $132(39.1)$ & $12(9.1)$ & $1.77(0.76-4.14)^{*}$ & $1.25(0.39-3.89)$ & 0.706 \\
\hline & No & $206(60.9)$ & $11(5.3)$ & 1 & 1 & \\
\hline
\end{tabular}

NB: *Candidate variable for multivariate analysis at $P<0.25$ *variable significant at $P<0.05$

COR crude odds ratio, AOR adjusted odds ratio, $C l$ confidence interval, $P$ - $V p$-value, 1 reference, STls sexual transmitted infections, yrs. years, No total number

(33.7\%) [21], Senegal (22\%) [17], and Côte d'Ivoire (9.1\%) [19], and a lower rate was reported in Kenya (1.1\%) [13]. The disparities in prevalence may be related to difference in composition of the studied population, distribution of risk factors, and effectiveness of STIs intervention programs [22].

The observed rate of co-infection of $N$. gonorrhoeae and C. trachomatis in the current study (0.6\%) was in agreement with the result reported in India (1.1\%) [23]. The occurrence of co-infection might be due to the fact that these bacteria share mode of transmission, and the presence of one infection could facilitate the acquisition of another [24].

It was also observed that the practice of using condom influenced the infection status with $N$. gonorrhoeae and C. trachomatis, where FCSWs, who regularly used condom, were more protected against the infections. This finding was also supported by the study from China [25].

Both $N$. gonorrhoeae and C. trachomatis infections were detected more frequently among FCSWs in the age range 15-24 years, though difference by age was not statistically significant. This finding was also compatible with the result reported in a similar study from China [26]. In contrast to our finding, infections were more likely detected among participants in the age range $\geq 35$ years in Korea [27]. A higher prevalence of $N$. gonorrhoeae and C. trachomatis among younger age group in our study might be related to having more number of sex clients per week and a lower level of awareness to STIs prevention [28].

As reported elsewhere [26], FCSWs, who got divorced or widowed, had a higher rate of infection with $N$. gonorrhoeae and C. trachomatis compared to those who were 
never married. Lack of social and economic support might expose them to engage in sex work and experience sexual violence, which increases the risk of contracting STIs [29]. Further, in agreement to a study in Argentina [30], FCSWs, who inconsistently used condom with their regular partners, had higher rate of $N$. gonorrhoeae and C. trachomatis infections compared to those who consistently used condom.

Our study has some limitations. First, we used a rapid diagnostic test for detection of C. trachomatis and culture for $N$. gonorrhoeae, which are less sensitive than PCR assays to accurately report the burden of these infections. Second, some of the assessed variables are confounded by recall bias or social desirability bias, leading to inaccurate response. Third, as the study investigated FCSWs, who attended the confidential clinic, the generalizability of the finding is also limited. Fourth, antibiotic resistance testing was not performed in the current study due to lack of resources. Fifth, our study considered small sample size, which limits the precision of our prevalence estimate. Despite these shortcomings, this study generated relevant information in Ethiopian setting where epidemiological data on $N$. gonorrhoeae and $C$. trachomatis infection is scarce.

In conclusion, this epidemiological study documented a high prevalence of $N$. gonorrhoeae and $C$. trachomatis infections among FCSWs. The study also showed that FCSWs, who inconsistently used condom, were at higher risk of contracting $N$. gonorrhoeae and C. trachomatis infections. Therefore, the findings of this study call for intervention measures that reduce the transmission of the infections. We suggest to the Ministry of Health the importance of providing screening service for FCSWs to detect and mange asymptomatic cases. Further, the Regional Health Bureau, health facilities in Hawassa City, and the confidential clinic need to emphasize improving the current condom promotion activities.

\section{Acknowledgements}

The authors would like to thank Hawassa University for financial support and allowing us to use laboratory materials and supplies for laboratory investigations. The authors also extend their appreciation to the Hawassa Confidential Clinic for providing us support during data collection. The authors are most grateful to the study participants who took part in the study.

\section{Funding}

No funding was obtained. But, Hawassa University provided minimal finance to support its postgraduate students.

\section{Availability of data and materials}

We need the datasets and/or analyzed during the current study for future work and not shared as supplementary material.

\section{Authors' contributions}

AT and TS designed the study; AT and SH carried out the laboratory work; all authors performed the statistical analyses, interpretation, contributed to the write-up and approved the final version of the manuscript.

\section{Ethics approval and consent to participate}

Ethical approval was obtained from the Institutional Review Board of College of Medicine and Health Sciences, Hawassa University. Permission to conduct the study was also obtained from the confidential clinic. All participants were informed about the purpose and importance of the study. To ensure the confidentiality of participants' information, code numbers were used instead of identifiers. To ensure the voluntary participation of the study participants, a written informed consent was obtained from all study subjects. Consent to participate was not collected from parents /guardians for children (under 16 years of age) because the study participants are working or earn their living by their own not with their family and allowed to give an informed consent as stated in (National Research Review Guideline of Ethiopia,2014). The study incurred no cost to the study participants, and testing for N. gonorrhea and $C$ trachomatis was performed free of charge. Participants, who tested positive for any infection, were treated according to the national guidelines. They were also made aware of the preventive measures and requested to return to the clinic after 2 weeks for additional treatment.

Consent for publication

Not applicable.

\section{Competing interests}

The authors declare that they have no competing interests.

\section{Publisher's Note}

Springer Nature remains neutral with regard to jurisdictional claims in published maps and institutional affiliations.

\section{Author details}

'Department of Medical Laboratory Science, Hawassa College of Health Sciences, South Nations and Nationalities Peoples Region, Hawassa, Ethiopia. ${ }^{2}$ School of Medical Laboratory Science, College of Medicine and Health Sciences, Hawassa University, Hawassa, Ethiopia.

Received: 8 August 2018 Accepted: 9 January 2019

Published online: 17 January 2019

\section{References}

1. Organization WH. Prevalence and incidence of selected sexually transmitted infections: Chlamydia trachomatis, Neisseria gonorrhoeae, syphilis and trichomonas vaginalis: methods and results used by WHO to generate 2005 estimates. Prevalence and incidence of selected sexually transmitted infections: Chlamydia trachomatis, Neisseria gonorrhoeae, syphilis and trichomonas vaginalis: methods and results used by WHO to generate 2005 estimates. 2011.

2. World Health Organization. Global prevalence and incidence of selected curable sexually transmitted diseases: overview and estimates. Geneva: WHO/GPA/STD 951 Rev 1; 1995.

3. Newman L, Rowley J, Vander Hoorn S, Wijesooriya NS, Unemo M, Low N, et al. Global estimates of the prevalence and incidence of four curable sexually transmitted infections in 2012 based on systematic review and global reporting. PLoS One. 2015;10(12):e0143304.

4. World Health Organization. Global incidence and prevalence of selected curable sexually transmitted infections-2008. Global incidence and prevalence of selected curable. Sex Transm Infect. 2008;19-20.

5. Kakar S, Bhalla P, Maria A, Rana M, Chawla R, Mathur N. Chlamydia trachomatis causing neonatal conjunctivitis in a tertiary care center. Indian J Med Microbiol. 2010;28(1):45

6. van Rooijen MS, van der Loeff MFS, Morré SA, van Dam AP, Speksnijder AG, de Vries HJ. Spontaneous pharyngeal Chlamydia trachomatis RNA clearance. A cross-sectional study followed by a cohort study of untreated STI clinic patients in Amsterdam, the Netherlands. Sex Transm Infect. 2015; 91(3):157-64.

7. Parvez F, Katyal M, Alper H, Leibowitz R, Venters H. Female sex workers incarcerated in New York City jails: prevalence of sexually transmitted infections and associated risk behaviors. Sex Transm Infect. 2013;89(4):280-4.

8. Wang H, Chen RY, Ding G, Ma Y, Ma J, Jiao JH, et al. Prevalence and predictors of HIV infection among female sex workers in Kaiyuan City, Yunnan Province, China. Int J Infect Dis. 2009;13(2):162-9. 
9. Fernandes FR, Mousquer GJ, Castro LS, Puga MA, Tanaka TS, Rezende GR, et al. HIV seroprevalence and high-risk sexual behavior among female sex workers in Central Brazil. AIDS Care. 2014;26(9):1095-9.

10. Kinsler JJ, Blas MM, Cabral A, Carcamo C, Halsey N, Brown B. Understanding STI risk and condom use patterns by partner type among female sex workers in Peru. Open AIDS J. 2014;8:17.

11. Tadesse E, Teshome M, Amsalu A, Shimelis T. Genital Chlamydia trachomatis infection among women of reproductive age attending the gynecology Clinic of Hawassa University Referral Hospital. Southern Ethiopia PloS one. 2016;11(12):e0168580.

12. Vandepitte JM, Malele F, Kivuvu D-M, Edidi S, Muwonga J, Lepira F, et al. HIV and other sexually transmitted infections among female sex workers in Kinshasa, Democratic Republic of Congo, in 2002. Sex Transm Dis. 2007;34(4):203-8.

13. Musyoki H, Kellogg TA, Geibel S, Muraguri N, Okal J, Tun W, et al. Prevalence of HIV, sexually transmitted infections, and risk behaviours among female sex workers in Nairobi, Kenya: results of a respondent driven sampling study. AIDS Behav. 2015;19(1):46-58.

14. Fonck K, Kaul R, Keli F, Bwayo JJ, Ngugi EN, Moses S, et al. Sexually transmitted infections and vaginal douching in a population of female sex workers in Nairobi, Kenya. Sex Transm Infect. 2001;77(4):271-5.

15. Verscheijden MM, Woestenberg PJ, Götz HM, van Veen MG, Koedijk FD, van Benthem BH. Sexually transmitted infections among female sex workers tested at STI clinics in the Netherlands, 2006-2013. Emerg Themes Epidemiol. 2015;12(1):12.

16. Vall-Mayans M, Villa M, Saravanya M, Loureiro E, Merono M, Arellano E, et al. Sexually transmitted Chlamydia trachomatis, Neisseria gonorrhoeae, and HIV-1 infections in two at-risk populations in Barcelona: female street prostitutes and STI clinic attendees. Int J Infect Dis. 2007;11(2):115-22.

17. Laurent C, Seck K, Coumba N, Kane T, Samb N, Wade A, et al. Prevalence of HIV and other sexually transmitted infections, and risk behaviours in unregistered sex workers in Dakar, Senegal. AIDS. 2003;17(12):1811-6.

18. Vuylsteke B, Semdé G, Sika L, Crucitti T, Traoré VE, Buvé A, et al. HIV and STI prevalence among female sex workers in cote d'voire: why targeted prevention programs should be continued and strengthened. PLoS One. 2012;7(3):e32627.

19. Uribe-Salas F, Hernández-Avila M, Conde-González C, Juárez-Figueroa L, Allen B, Anaya-Ocampo R, et al. Low prevalences of HIV infection and sexually transmitted disease among female commercial sex workers in Mexico City. Am J Public Health. 1997;87(6):1012-5.

20. Cárcamo CP, Campos PE, García PJ, Hughes JP, Garnett GP, Holmes KK, et al. Prevalences of sexually transmitted infections in young adults and female sex workers in Peru: a national population-based survey. Lancet Infect Dis. 2012;12(10):765-73.

21. Deceuninck G, Asamoah-Adu C, Khonde N, Pépin J, Frost EH, Deslandes S, et al. Improvement of clinical algorithms for the diagnosis of Neisseria gonorrhoeae and Chlamydia trachomatis by the use of gram-stained smears among female sex Workers in Accra, Ghana. Sex Transm Dis. 2000;27(7):401-10.

22. Johnson $L$, Coetzee $D$, Dorrington R. Sentinel surveillance of sexually transmitted infections in South Africa: a review. Sex Transm Infect. 2005;81(4):287-93.

23. Bala M, Mullick JB, Muralidhar S, Kumar J, Ramesh V. Gonorrhoea \& its coinfection with other ulcerative, non-ulcerative sexually transmitted \& HIV infection in a Regional STD Centre. Indian J Med Res. 2011;133(3):346.

24. Ness RB, Kip KE, Soper DE, Hillier S, Stamm CA, Sweet RL, et al. Bacterial vaginosis (BV) and the risk of incident gonococcal or chlamydial genital infection in a predominantly black population. Sex Transm Dis. 2005;32(7):413-7.

25. Luo L, Li X, Zhang L-I. Neisseria gonorrhoeae prevalence, incidence and associated risk factors among female sex workers in a high HIV-prevalence area of China. Int J Infect Dis. 2015;38:115-20.

26. Tang W, Pan J, Jiang N, Hu H-Y, Mahapatra T, Yin Y-P, et al. Correlates of chlamydia and gonorrhea infection among female sex workers: the untold story of Jiangsu, China. PLoS One. 2014;9(1):e85985.

27. Lee J, Jung S-Y, Kwon DS, Jung M, Park B-J. Condom use and prevalence of genital Chlamydia trachomatis among the Korean female sex workers. Epidemiol and Health. 2010;32:3-5.

28. Pettifor AE, Turner AN, Van Damme K, Hatzell-Hoke T, Rasamindrakotroka A, Nasution MD, et al. Increased risk of chlamydial and gonococcal infection in adolescent sex workers in Madagascar. Sex Transm Dis. 2007;34(7):475-8.

29. Nyagero J, Wangila S, Kutai V, Olango S. Behaviour change and associated factors among female sex workers in Kenya. Pan Afr Med J. 2012;13:1-9.

30. Pando MA, Berini C, Bibini M, Fernandez M, Reinaga E, Maulen S, et al. Prevalence of HIV and other sexually transmitted infections among female commercial sex workers in Argentina. Am J Trop Med Hyg. 2006;74(2):233-8.

Ready to submit your research? Choose BMC and benefit from:

- fast, convenient online submission

- thorough peer review by experienced researchers in your field

- rapid publication on acceptance

- support for research data, including large and complex data types

- gold Open Access which fosters wider collaboration and increased citations

- maximum visibility for your research: over $100 \mathrm{M}$ website views per year

At BMC, research is always in progress.

Learn more biomedcentral.com/submissions 